\title{
ИНЖЕНЕРНО-ГЕОЛОГИЧЕСКИЕ УСЛОВИЯ ДОЛИНЫ РЕКИ НЕМАН И ПРИЛЕГАЮЩИХ ТЕРРИТОРИЙ В ПРЕДЕЛАХ БЕЛАРУСИ
}

\author{
Т. А. Мележ \\ Учреждение образования «Гомельский государственный университет \\ имени Франциска Скорины», Республика Беларусь
}

Поступила в редакцию 23 апреля 2018 г.

\begin{abstract}
Аннотация: рассмотрены особенности формирования и пространственной дифференщиации инженерно-геологических условий, выделены генетические типь грунтовых толщ: озерноледниковые, водно-ледниковые, моренные, аллювиальные, озерные и болотные, Проанализированы физико-механические свойства грунтов и дана оценка их использования как оснований инженерных сооружений. Определено, что в пределах речной долины Немана иелесообразно в качестве естественных оснований зданий и сооружений использовать суглинистые, супесчаные и песчаные отложения различного генезиса, а также озерно-ледниковые ленточные глины, а широко распространенные на изучаемой территории болотные отложения использовать в качестве естественных оснований крайне нежелательно.

Ключевые слова: инженерно-геологические условия, грунты, физические свойства, генетические типы отложений.
\end{abstract}

\section{ENGINEERING-GEOLOGICAL CONDITIONS OF THE VALLEY OF THE RIVER NEMUNAS AND THE SURROUNDING AREAS IN BELARUS}

\begin{abstract}
: features of formation and spatial differentiation of engineering-geological conditions are considered, genetic types of soil thickness are allocated: ozerno-glacial, water-glacial, moraine, alluvial, lake and marsh, physical and mechanical properties of soils are Analyzed and the estimation of their use as the bases of engineering constructions is given. Determined that within the river valley of the Neman advisable as natural bases of buildings and constructions to use a loamy, sandy and sandy sediments of different Genesis, as well as glaciolacustrine clay belt, and widespread in the study area swamp deposits use as a natural reason highly undesirable.
\end{abstract}

Key words: geotechnical conditions, soil physical properties, genetic types of deposits.

\section{Введение}

Река Неман берет свое начало на южных склонах Минской возвышенности на абсолютных отметках 305-310 м в двух километрах к северо-западу от д. Шишки Дзержинского района Минской области. Истоком Немана является река Усса, которая, сливаясь с рекой Лоша, в одном километре выше д. Песочное Копыльского района Минской области, образует водный поток, называемый - Неман. Река пересекает три государства - Беларусь, Россию, Литву и впадает в Куршикий залив Балтийского моря. Протяженность реки на территории Беларуси - 431 км.

Река имеет разработанную долину с серией хорошо развитых террас. Характер строения долины реки на различных участках своеобразен, что связано с особенностями формирования Неманского речного бассейна. Развитие речной долины Немана связано с поозерским (валдайским) оледенением. Во время наступания ледника до границы его предельного распространения в долине Немана существовали обширные приледниковые бассейны, а его притоками осу- ществлялся сток талых ледниковых вод. Долина Немана формировалась вслед отступающему леднику - прогрессивно. Современная долина Немана начала формироваться в связи с отступанием сожского ледника от краевых образований юго-западных ответвлений Белорусской гряды и до настоящего времени.

\section{Цель исследования}

Выявить особенности инженерно-геологических условий долины реки Неман в пределах Беларуси и определить физические свойства грунтовых толщ.

\section{Материал и методы исследования}

В основу исследования положены результаты инженерно-геологических изысканий, проводимых в долине реки Неман, картографический материал: топографические карты, геоморфологическая карта и карта четвертичных отложений Беларуси. Для анализа особенностей инженерно-геологических условий долины реки Неман и прилегающих территорий использовались экспедиционные работы, картографически 
методы и метод системного анализа.

\section{Результаты исследования}

Инженерно-геологическое строение долины реки Неман весьма разнообразно и определяется особенностями рельефа, геологическим строением и физикомеханическими свойствами пород. На основе анализа указанных факторов изучаемую территорию можно разделить на четыре крупных района (рис. 1):

1) район развития озерно-ледниковых отложений - $\lg Q_{3} p z$ (глины, суглинки, супеси, пески);

2) район развития водно-ледниковых отложений $f g Q_{3} p z, f g Q_{2} s z, \quad k m Q_{3} p z$ (пески, песчано-гравийные породы);

3) район развития моренных отложений $-g Q_{2} s z$, $g t Q_{2} s z$ (супеси, суглинки моренные, пески, песчаногравийные породы);

4) район развития аллювиальных, озерных и болотных отложений $-f I Q_{4}, f Q_{3} p z, l f Q_{3-4} p z, p l Q_{4}$ (пески, супеси, суглинки, глины, торф, илы, сапропели).

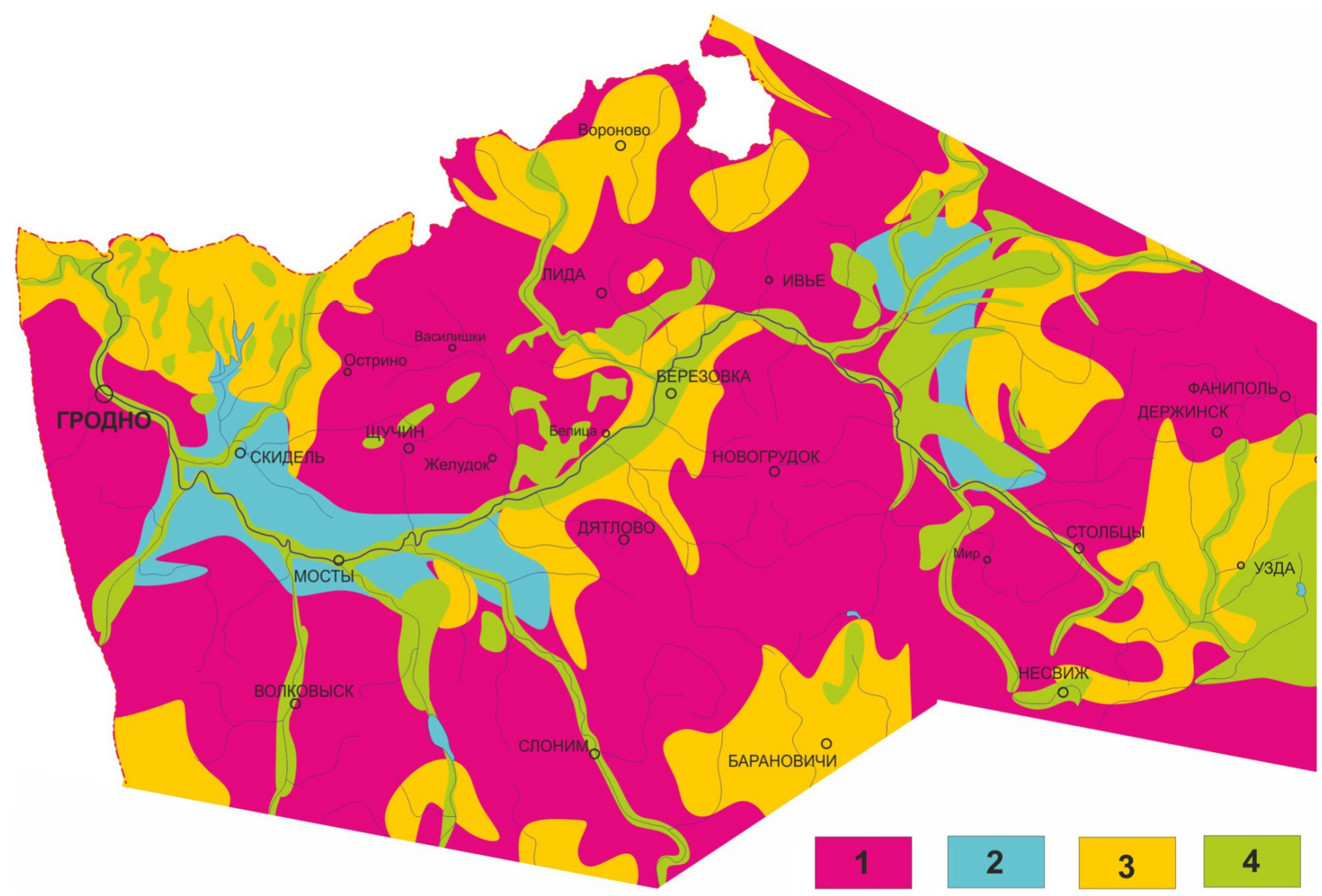

Puc. 1. Картосхема районов распространения генетических типов четвертичных отложений: 1 - район развития озерноледниковых отложений; 2 - район развития водно-ледниковых отложений; 3 - район развития моренных отложений; 4 - район развития аллювиальных, озерных и болотных отложений (составлено автором по данным [2]).

Озерно-ледниковые отложения залегают обычно на морене в верхней части четвертичной толщи и только местами перекрываются маломощным чехлом голоценовых отложений. В литологическом составе преобладают супеси, суглинки, пески и глины. Мощность отложений изменяется от 0,5 до 2,3 м, но в отдельных крупных депрессиях увеличивается до 15-20 м.

Озерно-ледниковые образования чаще всего окрашены в различные оттенки коричневого, бурого, реже серого цветов. Отличительной особенностью является широкое развитие в них так называемых ленточных глин. Такие текстуры характеризуются закономерным ритмическим чередованием прослоев глинистого и пылевато-песчанистого материала [1].

Характерной особенностью гранулометрического состава практически всех озерно-ледниковых грунтов является полное преобладание частиц размерностью менее 0,1 мм над остальными, что сопряжено с их текстурными особенностями и предопределяет склонность к пучению или промерзанию.

В минеральном составе грубодисперсной фракции преобладает кварц, тонкодисперсной - иллит. В ленточных глинах фиксируется до $20 \%$ карбонатов, что объясняется влиянием эрозионной деятельности ледника на известково-доломитовую толщу верхнего девона и мергельно-меловые отложения меловой системы. Породы слаболитифицированы. На упрочнение пород в верхней зоне, на глубине 1,5-2 м существенное влияние оказывают процессы выветривания. В общем, толща озерно-ледниковых отложений характеризуется высокой неоднородностью физических свойств (табл. 1). 
范

\begin{tabular}{|c|c|c|c|c|}
\hline 。옹 & 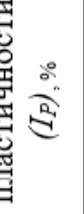 & 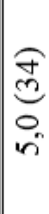 & 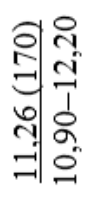 & 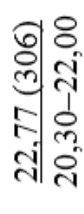 \\
\hline 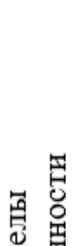 & 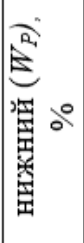 & ' & ' & 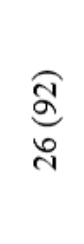 \\
\hline 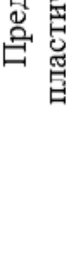 & 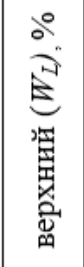 & $\begin{array}{l}\text { f } \\
\text { a } \\
a \\
\text { యे }\end{array}$ & 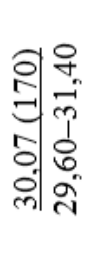 & 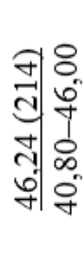 \\
\hline $\begin{array}{l}\text { 虽 } \\
\text { 岕 } \\
\text { 苞 }\end{array}$ & 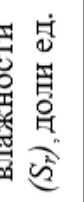 & ڤ్ & 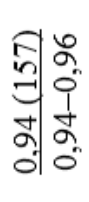 & 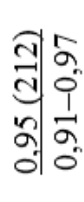 \\
\hline 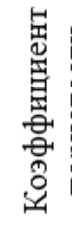 & 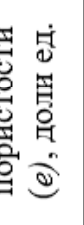 & $\begin{array}{l}\text { กิ } \\
\text { n } \\
n \\
0\end{array}$ & 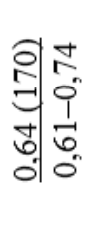 & 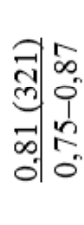 \\
\hline $\begin{array}{l}\text { 念 } \\
\text { 足 } \\
\text { 至 }\end{array}$ & 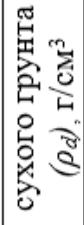 & 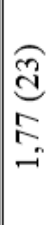 & 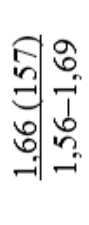 & 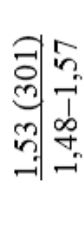 \\
\hline 口 & 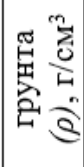 & 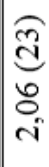 & 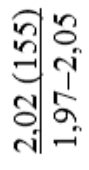 & 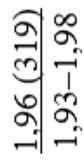 \\
\hline \multicolumn{2}{|c|}{ 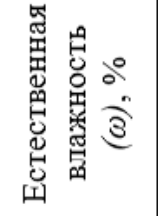 } & 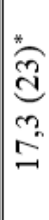 & 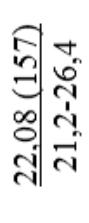 & 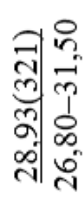 \\
\hline \multicolumn{2}{|c|}{ 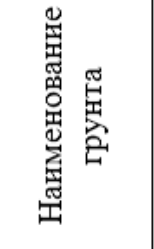 } & 导 & 总 & 焉 \\
\hline
\end{tabular}

夢
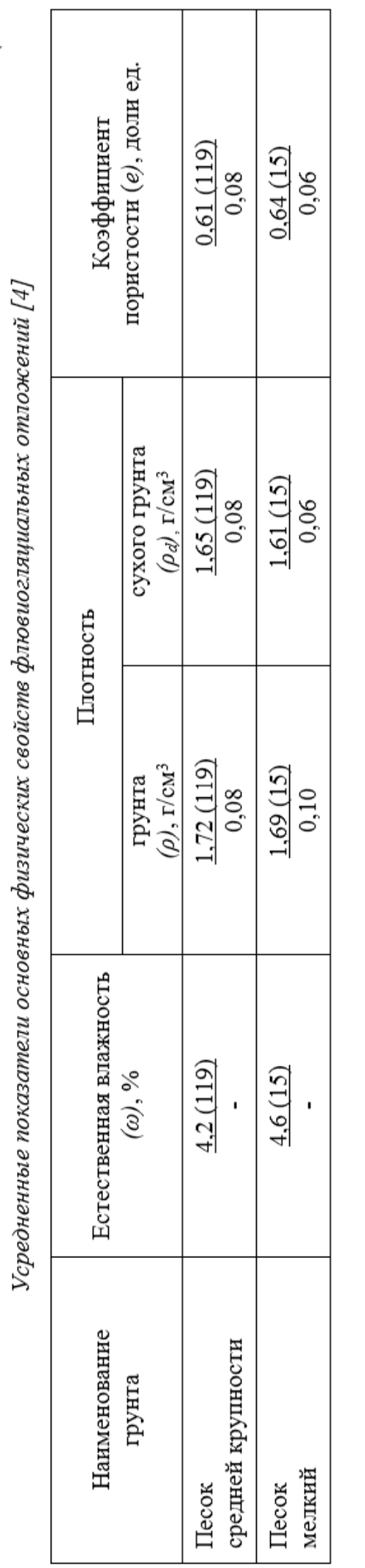

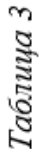

离

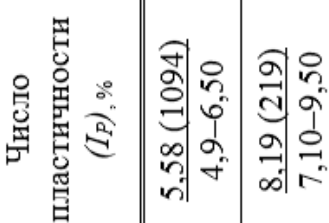

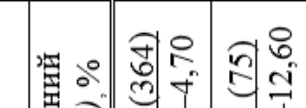

署急

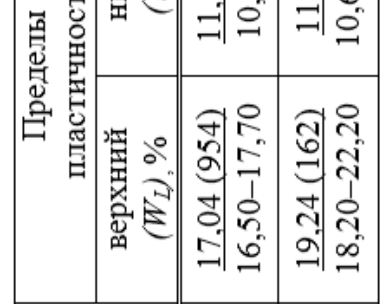

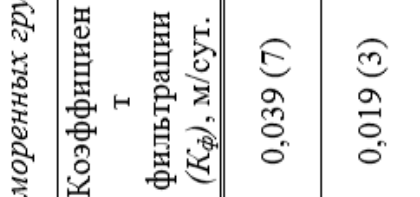

$\cong$

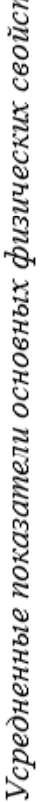

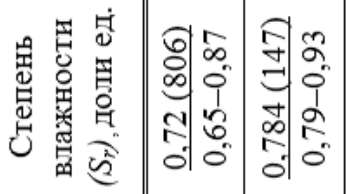

ब.

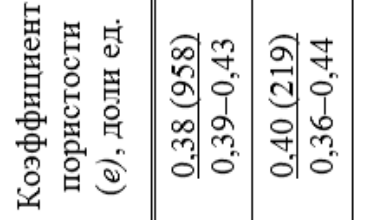

\begin{tabular}{|c|c|c|c|}
\hline $\begin{array}{l}\text { 雚 } \\
\text { 足 }\end{array}$ & 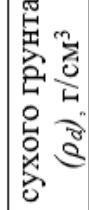 & 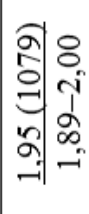 & 형 \\
\hline 香 & 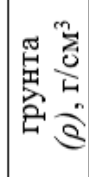 & 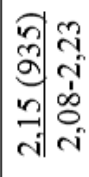 & 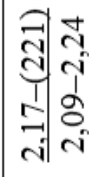 \\
\hline & & 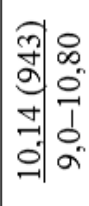 & 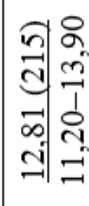 \\
\hline 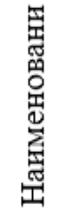 & 营 & $\begin{array}{l}\text { 总 } \\
\text { 䍐 }\end{array}$ & \\
\hline
\end{tabular}


Основные показатели физико-механических свойств грунтов озерно-ледникового генезиса: плот-

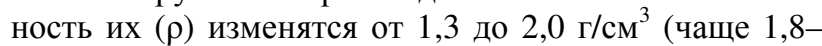

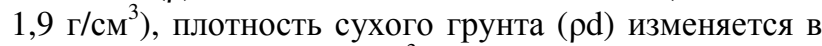

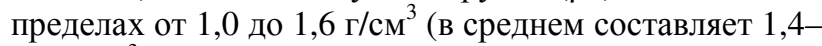

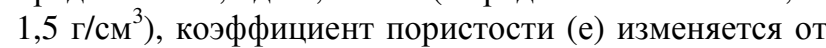
0,47 до 1,20 , в единичных случаях достигает 2 и более (чаще $0,6-0,9$ ) [3].

Значение естественной влажности глин $(\omega)$ варьирует в пределах - 30-45\% (иногда достигает 60-70 $\%)$, супесей - 22-28 \%, песков - колеблется от 3-10\% в зоне аэрации и до 22-32 \% ниже уровня грунтовых вод [4].

В большинстве случаев отложения приледниковых озер находятся в состоянии близком к полному водонасыщению. Естественная влажность ленточных глин почти всегда превышает нижний, а во многих случаях и верхний пределы пластичности (табл. 1). В последнем случае глины находятся в скрытотекучем состоянии, при нарушении их естественной структуры переходят в текучее состояние. Со слоистым строением пород связана резко выраженная анизотропия свойств. Например, в горизонтальном направлении они водопроницаемы, а в вертикальном практически водоупорны.

Для песчаных и пылеватых прослоев, определяющих водопроницаемость вдоль прослоев, коэффициенты фильтрации $(K \phi)$ изменяются от $10^{-4}$ до $10^{-6}$ см/с, а у глинистых снижается до $10^{-8} \mathrm{~cm} / \mathrm{c}$.

Ленточные глины быстро размокают, в откосах при увлажнении образуют оползни, сплывы, потоки. Величина набухания ленточных образований из-за иллитового состава незначительна и не превышает 5-10\%.

Озерно-ледниковые суглинки и глины обладают повышенной и весьма неоднородной сжимаемостью. Модуль деформации в интервалах удельных нагрузок 0,1-0,2 МПа изменяется от 5,3 до 25,1 для суглинков и от 1,5 до 12,2 МПа для глин. По результатам штамповых испытаний модуль деформации глинистых грунтов значительно выше и составляет соответственно 20,0-29,0 МПа при пределе линейной пропорциональности между нагрузкой и осадкой штампа $2,0-3,5 \times 10^{5}$ Па для суглинков и 10,0-20,0 МПа при пределе пропорциональности 0,15-0,2 МПа для глин.

Супеси и пески обладают главным образом средней сжимаемостью: модуль общей деформации супесей по компрессионным испытаниям в интервале нагрузок 0,1-0,2 МПа составляет 10,9-25,5 МПа, песков - 9,2-26,6 МПа [3, 4]. По результатам штамповых испытаний в условиях естественного залегания они характеризуются более высокими деформационными свойствами.

Грунты озерно-ледникового генезиса, представленные песчано-супесчаными разностями, могут служить вполне удовлетворительным основанием для большинства промышленных и гражданских объектов. Ленточные глины и суглинки с позиции использования их как оснований для инженерных сооружений являются более слабыми породами. При проекти- ровании оснований и возведении на них инженерных сооружений с ленточными и столбчатыми фундаментами необходимо ограничивать предельные нагрузки в пределах 0,15-0,2 МПа и обращать внимание на сохранение природного сложения, не допускать искусственного увлажнения, промерзания, динамических воздействий и прочее. При строительстве на ленточных глинах небольшой мощности целесообразно применять свайные фундаменты с опиранием свай на моренные грунты и другие более прочные естественные основания.

Водно-ледниковые отложения представляют собой образования талых вод ледника, прошедших через толщу льда по трещинам и двигавшимися подо льдом к его краю. Эти воды вымывали из толщи льда обломки пород и накапливали их вдоль движущегося потока по днищу ледникового трога, образуя озы и камы, протяженностью несколько километров при небольшой ширине в несколько метров. На флювиогляциальные отложения приходится почти треть объема антропогеновой толщи.

Флювиогляциальные отложения достаточно широко распространены в пределах изучаемой территории. Они представлены группами образований, сформировавшимися в различных фациальных обстановках. Это отложения фливиокамов и камовых террас, озов, краевых гряд, долинные и покровные флювиогляциальные аккумуляции.

Наибольший интерес с точки зрения инженерногеологических исследований представляют зандровые отложения, мощность которых варьирует от долей метра до 20-25 м, иногда более. В литологическом отношении представлены суглинками, супесями, песчано-гравийными породами, но, как правило, преобладают пески. Иногда в зандрах наблюдается сравнительно тонкое переслаивание песчано-гравийногалечного материала, песков разной крупности и отдельных прослоев супесей и суглинков.

Пески преимущественно плотного сложения и средней плотности (по ГОСТ 25100-2011) (табл. 2). Водопроницаемость песков в зависимости от гранулометрического состава изменяется от первых единиц до десятков метров в сутки. Сжимаемость песков слабая, реже средняя. По данным штамповых испытаний, модуль общей деформации песков колеблется от 2540 МПа (средней плотности пески) до 40-80 МПа (для плотных песков), для рыхлых песков модуль деформации составляет не более 20 МПа [3, 4].

В целом, по своим свойствам грунты флювиогляциального генезиса, главным образом, пески, близки к пескам других генетических типов, отличаясь от них несколько большей плотностью.

Основные физико-механические свойства (табл. 2): плотность флювиогляциальных песков ( $\rho)$ при естественной влажности изменяется от 1,8 до 2,1 г/см ${ }^{3}$

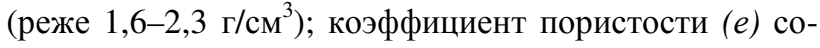
ставляет 0,5-0,8. Естественная влажность флювиогляциальных песков $(\omega)$ изменяется от 3 до $8 \%$ в зоне аэрации и до 20-30 \% (в среднем $25 \%$ ) в водонасы- 
щенном состоянии. Коэффициент фильтрации $\left(K_{\phi}\right)$ флювиогляциальных песков, как правило, несколько выше, чем у песков других генетических типов ледниковых отложений и изменяется от первых единиц до десятков метров в сутки. Флювиогляциальным песчаным отложениям свойственны сравнительно высокие углы внутреннего трения $(\varphi)$ от 23 до $45^{\circ}$ (в среднем 27-35 ); коэффициент внутреннего трения $(f)$ изменяется в пределах от 0,86 до 1,0 (в среднем $0,50-$ $0,7)$. Сцепление $(C)$ у песков измеряется преимущественно тысячными долями, но в единичных случаях достигает 0,01-0,02 МПа (в том числе за счет слабой цементации). Общий модуль деформации флювиогляциальных песков $(E)$ составляет 30-70 МПа (в отдельных случаях достигает 100-120 МПа) [3].

Суглинки и супеси, встречающиеся в толще песков в виде отдельных прослоев и линз, отличаются непостоянством состава и свойств. Модули деформации $(E)$ у них обычно много ниже, чем у песков, и изменяются в широких пределах: от 7 до $33 \mathrm{MПа} \mathrm{(в}$ среднем 12-18 МПа) у супесей, от 6 до 16 МПа (обычно 8-12 МПа) у суглинков [4].

Флювиогляциальные пески обладают вполне удовлетворительными инженерно-геологическими свойствами и могут служить надежным основанием для различных инженерных сооружений.

Моренные отложения в долине Немана размыты, залегают преимущественно на днепровско-сожских, днепровских, березинских образованиях и редко на коренных породах, перекрываются более молодыми сожско-поозерскими водно-ледниковыми, поозерскоголоценовыми аллювиальными и озерно-аллювиальными отложениями. Мощность морены изменяется от 0,2-0,5 до 80-100 м, в пределах возвышенностей возрастает до 135 м, в среднем мощность составляет 10$25 \mathrm{M}$.

Конечные морены сложены преимущественно валунными супесями, разнозернистыми песками с гравием, галькой и валунами, песчано-гравийным и гравийно-галечным материалом. Песчаные и гравийные толщи разбиты трещинами, отдельные блоки и пачки перевернуты, сдвинуты, иногда смяты, разорваны. В супесях наблюдаются гнезда и линзы глинистых песков, глыбы сцементированного песчано-гравийного материала. В ледниковой толще отмечаются отторженцы более древних четвертичных отложений и коренных пород, крупные гляциодислокации (гг. Гродно, Мосты, Дятлово, Новогрудок).

В сожском ледниковом комплексе наблюдаются сменяющиеся горизонты - основная морена - потоковая морена, основная морена - потоковая морена. Цвет отложений темно-бурый, редко буровато-серый, желтовато-бурый и коричнево-бурый [5].

Сожская морена залегает на флювиогляциальных породах, сложена она валунными супесями бурого, буровато-серого и зеленовато-серого цвета. Уменьшений мощности сожской морены связано с ее размывом при накоплении потоковой морены. Эта морена представлена гравийно-галечным материалом и различными песками, содержащими гравий и гальку до 10-25 \%; встречаются небольшие линзы мелких песков светло-желтого цвета и гравийно-галечный материал.

В западинах сожской потоковой морены встречаются озерные и болотно-торфянистые накопления торф черного цвета, супеси гумусированные темносерые и супеси голубовато-серые, накопленные в муравинское межледниковье [5].

Усредненные значения физико-механические свойства грунтов (табл. 3) ледникового генезиса (сожская морена): плотность ( $\rho)$ при естественной влажно-

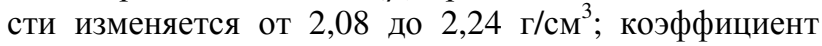
пористости (e) составляет 0,36-0,44; естественная влажность моренных супесей и суглинков $(\omega)$ изменяется от 9 до 13,9 \% в зоне аэрации. Коэффициент фильтрации $\left(K_{\phi}\right)$ составляет 0,039 м/сут - для супесей и 0,019 - для суглинков. Моренным супесям и суглинкам свойственны сравнительно невысокие углы внутреннего трения $(\varphi)$ от 27 до $32^{\circ}$ (в среднем $30^{\circ}$ ); сцепление $(C)$ у супесей - 0,03-0,05 МПа, в среднем 0,037, для суглинков - 0,028 МПа [3, 4]. Из-за неоднородности и высокого содержания пылеватых частиц моренные отложения способны быстро размокать, при промерзании склонны к пучению.

Согласно проведенным инженерно-геологическим изысканиям установлена вертикальная зональность в строении моренных толщ. Так, Г.Л. Кофф отмечает, что по данным динамического зондирования и временного сопротивления одноосному сжатию в вертикальных разрезах моренных отложений выделяют верхнюю, переходную и нижнюю зоны. Мощность верхней зоны изменяется от 0,5-1,0 до 2,0-4,0 м, переходной от 0 до 2,0-3,0 м. Для отложений верхней зоны характерны значения временного сопротивления образцов одноосному сжатию - 0,01-0,13 МПа, для нижней зоны - от 0,08-0,2 до 0,5 МПа. По направлению к верхней зоне отмечается снижение значений модуля деформации с 20-40 до 6-15 МПа, и как следствие уменьшаются прочностные характеристики грунтов [3].

Возникновение инженерно-геологических опасностей в моренных грунтах, главным образом, связано с неоднородностью их состава, структуры и текстуры; присутствием внутриморенных водоносных песчаных прослоев, содержащих напорные воды, и линз слабых мягких глин и суглинков; с относительно более низкими прочностными и деформационными свойствами морены. При промерзании грунты сильно пучатся. При увеличении влажности ухудшаются показатели их механических свойств. Повышение гидравлических градиентов в водовмещающих породах, представленных слоями или линзами песков в гляциальных отложениях, при условии их вскрытия котлованами или горными выработками может способствовать формированию плывунов. Способность глинистых отложений кон-центрировать в себе поверхностный сток, а также их легкая размываемость приводят при расчлененном рельефе к 
развитию овражно-балочной сети. Эта особенность ярко проявляется в районах развития краевых ледниковых образований. В зоне распространения ледниковой формации формируются оползни.

Главными осложняющими факторами при строительстве на моренных грунтах являются неоднородность их состава, наличие переменного количества крупнообломочного материала, склонность к размоканию и пучению при промерзании и как следствие возможные деформации зданий и сооружений, построенных на этих грунтах.

Аллювиальные отложения представляют собой результат переработки озерно-ледниковых, флювиогляциальных и моренных образований. Плейстоценовые оледенения оказали существенное влияние на фациальную структуру и вещественный состав аллювия. Ледниковые покровы, двигаясь к югу и юго-востоку, вызывали подпруживание рек, текущих им навстречу, что приводило к образованию в долинах озер. В связи с этим в строении речных террас, формировавшихся в эпохи оледенений (в особенности, верхнеплейстоценовых) в долинах рек бассейна Балтийского моря, большое участие принимают озерно-аллювиальные отложения. В подошве обычно залегают осадки базальной пристрежневой фаций аллювия, среди которых преобладают разнозернистые пески с галечником в основании. Перекрывающая их основная часть отложений, имеющая более широкое площадное распространение, представлена чередованием аллювиальных песков с озерными суглинками, супесями и глинами часто ленточной текстуры.

Голоценовый аллювий в сравнении с аллювием ледниковых эпох отличается более четкой фациальной и механической дифференциацией осадков. В этом комплексе выделяют три главнейших фациальных типа осадков: русловой; прирусловой; пойменный и старичный аллювий

Пойменный и старичный аллювий формируются во время половодий. Для пойменных отложений характерен песчано-алевритовый состав осадков с текстурами течений, волнений и ряби.

По гранулометрическому составу пески, доминирующие среди современных аллювиальных образований, напоминают подобные аллювиальные породы плейстоценового возраста, хотя и несколько отличаются более широким распространением мелкозернистых разностей и большим содержанием алевритоглинистых примесей. Содержание частиц меньше 0,05 мм в большинстве случаев составляет 5-20\%; на фракцию 0,1-0,05 мм приходится 5-25\%. Фракция 0,25-0,1 мм часто является основной (40-92\%). Для частиц размером 0,5-0,25 мм наиболее характерны содержание от 2 до $25 \%$ [3, 4]. Количество более крупных фракций непостоянно.

Встречающиеся в аллювии линзы песчаногравийно-галечного материала в среднем содержат порядка 2,5 \% валунов, 12-30 \% галек, 25-45 \% гравия, 30-60 \% зерен песчаной размерности и около 2-7 $\%$ алеврито-глинистых частиц [4].
В районах распространения краевых ледниковых образований в толще аллювия появляются линзы, прослои или гнезда крупнообломочного материала. Гранулометрические параметры этого материала сходны с параметрами потоково-ледниковых песчаногравийно-галечных отложений, отличаясь либо несколько меньшим содержанием валунов и крупных галек, а также большей однородностью.

Озерные отложения. Важное место в осадконакоплении принадлежит озерам. В озерах накапливаются минеральные, органо-минеральные и органические осадки. Они представлены разнозернистыми песками (преимущественно мелко-тонкозернистыми), нередко карбонатными, заиленными, а также супесями, глинами, илами и сапропелями. Средняя мощность толщи озерных аккумуляций может варьировать от 3 до 7 м, максимальная достигает 20-25 м и более.

Формирование геологических опасностей может быть связано с различным физическим состоянием пород по плотности, пористости, влажности и консистенции; анизотропией свойств, обусловленной слоистостью. Глинистые разности часто обогащены органикой и другими примесями.

Болотные отложения на изучаемой территории сложены, главным образом, верховыми и переходными торфяниками. Мощность торфяных залежей не выдержана и может изменяться от нескольких десятков сантиметров до нескольких метров. На моренных равнинах болотные отложения, как правило, отличаются меньшей мощностью и мозаичностью распространения. Самые мощные толщи болотных образований приурочены к заполненным осадками озерным котловинам [4].

Со строительной точки зрения болотные отложения относятся к группе грунтов особого состояния и свойств, которые лишь ограниченно могут использоваться в качестве естественных оснований зданий и сооружений из-за низкой прочности и высокой сжимаемости. При этом, как правило, приходится производить полную или частичную выторфовку с заменой торфа грунтами, обладающими удовлетворительными строительными свойствами, либо создавать отгрузку торфомассива с помощью отсыпки грунта на торф, для уплотнения последнего.

\section{Выводы}

Речная долина Немана отличается своеобразием инженерно-геологических условий, которые определяются особенностями рельефа, геологическим строением и физико-механическими свойствами грунтов. В пределах изучаемой территории выделены следующие генетические типы грунтовых толщ: озерноледниковые, водно-ледниковые, моренные, аллювиальные, озерные и болотные.

По каждой грунтовой толще проанализированы физико-механические свойства грунтов и дана оценка их использования как оснований инженерных сооружений. Так, грунты озерно-ледникового генезиса, 
представленные песчано-супесчаными разностями, могут служить вполне удовлетворительным основанием для большинства промышленных и гражданских объектов; грунтовые толщи флювиогляциального генезиса обладают вполне удовлетворительными инженерно-геологическими свойствами и могут служить надежным основанием для различных инженерных сооружений; моренные грунты характеризуются неоднородностью состава, наличием переменного количества крупнообломочного материала, склонностью к пучению при промерзании, также при увеличении влажности ухудшаются показатели их механических свойств и как следствие возможны деформации зданий и сооружений, построенных на этих грунтах; грунты аллювиального генезиса, главным образом старичные глинистые грунты, находящиеся преимущественно в мягкопластичном состоянии и обогащенные значительным количеством органики обладают неудовлетворительными инженерногеологическими характеристиками (грунты имеют высокую сжимаемость, низкие показатели сопротивления сдвигу, часто обладают тиксотропными свойствами), но в это же время грунты стариц надпойменных террас характеризуются более низкой влажностью и пористостью, большей уплотненностью и прочностью и характеризуются более благоприятными инженерно-геологическими свойствами; грунты болотного генезиса ограниченно могут использоваться в качестве естественных оснований зданий и сооружений из-за низкой прочности и высокой сжимаемости, использование торфяных грунтов в качестве оснований возможно для сооружений легких и малочувствительных к осадкам, тяжелые и чувствительные к осадкам сооружения должны опираться на минеральные грунты.

Таким образом, в пределах речной долины Немана целесообразно в качестве естественных оснований зданий и сооружений использовать суглинистые, су- песчаные и песчаные отложения различного генезиса, а также озерно-ледниковые ленточные глины, а широко распространенные на изучаемой территории болотные отложения, использовать в качестве естественных оснований крайне нежелательно.

Изучение особенностей инженерно-геологических условий имеет большое прикладное значение, поскольку с долиной Немана издавна связаны множество населённых пунктов, промышленное и гражданское строительство, создание гидротехнических сооружений, разработка месторождений полезных ископаемых и ведение сельского хозяйства. Следовательно, необходимо тщательное изучение долинного комплекса с точки зрения его инженернохозяйственного освоения, в частности изучение физико-механических свойств грунтов и определение наиболее пригодных в качестве оснований инженерных сооружений.

\section{ЛИТЕРАТУРА}

1. Мандер, Е.П. Антропогеновые отложения и развитие рельефа Белоруссии / Е. П. Мандер. - Минск: Наука и техника, 1973. - $128 \mathrm{c}$.

2. Чацвярцічныя адклады. М 1: 1250000 // Нацыянальны атлас Беларусі.- Мінск: Белкартаграфія, 2002. - С. 43.

3. Трацевская, Е.Ю. Региональная инженерная геология Беларуси: тексты лекций по спецкурсу для студентов специальности I-51 0101 «Геология и разведка месторождений полезных ископаемых» специализации I-51 010103 «Инженерная геология и гидрогеология» / Е. Ю. Трацевская // Министерство образования РБ, Гомельский гос. ун-т имени Франциска Скорины. - Гомель: ГГУ им. Ф. Скорины, 2008. $-143 \mathrm{c}$.

4. Галкин, А.Н. Инженерная геология Беларуси: монография: в 3 ч. / А.Н. Галкин. - Витебск: ВГУ им. П.М. Машерова, 2016. - Ч. 1: Грунты Беларуси / под науч. ред. В.А. Королева, 2016. - 367 с.

5. Гореияий, Г.И. Особенности палеопотамологии ледниковых областей (на примере Белорусского Понеманья) / Г.И. Горецкий. - Минск: Наука и техника, 1980. - 288 с.

Francisk Skorina Gomel State University, Republic of Belarus

Melezh T. A., Senior Lecturer of Geology and Geography Department

E-mail: tatyana.melezh@mail.ru 